\title{
Self-assembly of cobalt-centered metal organic framework and multiwalled carbon nanotubes hybrids as a highly active and corrosion-resistant bifunctional oxygen catalyst
}

Yiyun Fanga ${ }^{\mathrm{a}}$, Xinzhe $\mathrm{Li}^{\mathrm{a}}$, Feng $\mathrm{Li}^{\mathrm{a}}$, Xiaoqing $\mathrm{Lin}^{\mathrm{a}}$, Min Tian ${ }^{\mathrm{a}}$, Xuefeng Long ${ }^{\mathrm{a}}$, Xingcai $\mathrm{An}^{\mathrm{b}}$, Yan $\mathrm{Fu}^{\mathrm{c}}$, Jun $\mathrm{Jin}^{\mathrm{a}, *}$ and Jiantai $\mathrm{Ma}^{\mathrm{a}, *}$

a The Key Laboratory of Catalytic engineering of Gansu Province,College of Chemistry and Chemical Engineering, Lanzhou University, Lanzhou 730000, P.R. China

${ }^{b}$ Natural Energy Institute, Gansu Academy of Sciences, Lanzhou 730046, Gansu, P.R. China

${ }^{c}$ Northwest Yongxin Coatings Company Limited, Lanzhou 730046, Gansu, P.R. China

\section{Abstract:}

Metal organic frameworks (MOF) derived carbonaceous materials have emerged as promising bifunctional oxygen evolution reaction (OER) and oxygen reduction reaction (ORR) catalysts for electrochemical energy conversion and storage. But previous attempts to overcome the poor electrical conductivity of MOFs hybrids involve a harsh high-template pyrolytic process to in situ form carbon, which suffer from extremely complex operation and inevitable carbon corrosion at high positive potentials when OER is operated. Herein, a self-assembly approach is presented to synthesize a non-precious metal-based, high active and strong durable Co-MOF@CNTs bifunctional catalyst for OER and ORR. CNTs not only improve the transportation of the electrons but also can sustain the harsh oxidative environment of 
OER without carbon corrosion. Meanwhile, the unique 3D hierarchical structure offers a large surface area and stable anchoring sites for active centers and CNTs, which enables the superior durability of hybrid. Moreover, a synergistic catalysis of $\mathrm{Co}(\mathrm{II})$, organic ligands and CNTs will enhance the bifunctional electrocatalytic performance. Impressively, the hybrid exhibits comparable OER and ORR catalytic activity to $\mathrm{RuO}_{2}$ and $20 \mathrm{wt} \% \mathrm{Pt} / \mathrm{C}$ catalysts and superior stability. This facile and versatile strategy to fabricating MOF-based hybrids may be extended to other electrode materials for fuel cell and water splitting applications.

Keywords: Metal organic frameworks; multiwalled carbon nanotubes; 3D hierarchical structure; corrosion-resistant; bifunctional catalysts.

*Corresponding author:

E-mail: jinjun@1zu.edu.cn (J.Jin); majiantai@1zu.edu.cn (J. Ma);

Tel.: +86-931-8912577;

Fax: +86-931-8912582 


\section{Introduction}

Oxygen electrocatalysis is central to the development of efficient energy storage and conversion devices such as metal - air batteries and regenerative fuel cells to link intermittent renewable energy with energy needs on-demand [1-4]. However, progress is hampered by the sluggish kinetics of oxygen evolution reaction (OER) and oxygen reduction reaction (ORR) [5]. To date, the most active catalysts for both the OER and the ORR are primarily derived from the platinum group metals, such as $\mathrm{RuO}_{2}, \mathrm{IrO}_{2}$ and Pt $[6,7]$. Nevertheless, the high cost and scarcity as well as poor stability has restricted their widespread applications. Besides, a major drawback is that good catalysts for OER, such as $\mathrm{RuO}_{2}$, are often poor for ORR and vice versa, making it very challenging to realize materials that can serve as bifunctional catalysts for both OER and ORR.

With respect to the low cost, earth-abundant transition-metal oxides/hydroxides [8-10], especially Co-based complexes with different structures and dimensions [11-16], are explored as promising alternative catalysts for OER and ORR. However, the strong causticity in alkaline solution and intrinsic low conductivities of many Co-based catalysts hamper their further applications [17]. One recent strategy applied to improve the durability of these composites is to couple them with a conductive support such as graphene [10], carbon nanotubes [18], Ni foam [19]. Studying the general design of the catalysts, it can be seen that most of these conductive support-based composites are fabricated by direct deposition or adsorption of nanocatalysts on the substrates surface [20], yet the biggest problem is that the active 
centers are directly exposed and they are easily peeled off from the substrates surface during long-term electrochemical reactions, thus resulting in poor stability.

Recently, metal organic frameworks (MOFs), a class of crystalline inorganic organic hybrid materials, with diverse skeletons and fascinating properties such as well-defined pore structures, high surface areas and large pore volume, are very attractive for applications in catalysis. Moreover, MOFs contain redox-active metals and organic linkers as both redox and proton transfer mediator motifs for catalyzing water oxidation reaction [21]. And a synergistic catalysis of inorganic catalysts and ligands promotes oxygen-evolving systems. Nevertheless, the intrinsic conductivity of most MOFs is less desirable, which excludes them from being used as electrode materials or electrocatalysts. Previous attempts to improve the electrical conductivity of MOFs hybrids involve a harsh high-template pyrolytic process to in situ form carbon [22-27], which suffer from extremely complex operation and time-consuming fabrication. What's worse, carbon corrosion is inevitable and disastrous at high positive potentials when OER is operated in the electrolyzer mode as indicated by the following reaction $[28,29]$ :

$$
\mathrm{C}+2 \mathrm{H}_{2} \mathrm{O} \rightarrow \mathrm{CO}_{2}+4 \mathrm{H}^{+}+4 \mathrm{e}^{-}\left(\mathrm{E}^{\circ}=0.207 \mathrm{~V} \text { vs. NHE at } 25^{\circ} \mathrm{C}\right)
$$

Oxidation of carbon generally referred to as carbon corrosion, which can accelerate agglomeration or loss of active centers, thus decreasing the activity and lifetime of catalyst. Hence, seeking a direct and mild approach to prepare excellent MOFs-based catalyst for OER and ORR is desired. 
Based on the above reasons, we introduce a cobalt-containing zeolitic imidazolate framework (termed Co-MOF) and present a facile self-assembly approach to synthesize a high active and strong durable Co-MOF@CNTs bi-functional catalyst for OER and ORR. Co-MOF, which incorporates the nets of corner-sharing tetrahedral $\mathrm{CoN}_{4}$, where the bond between the benzimidazolate (phIM) anion and $\mathrm{Co}(\mathrm{II})$ is one of the most stable N-donor ligands. Besides, Co-MOF has an open-framework structure adopting sodalite topology with hexagonal symmetry, composed of bridging benzimidazolate anions and cobalt cations with the formula $\mathrm{Co}(\mathrm{PhIm})_{2} \cdot(\mathrm{DMF}) \cdot\left(\mathrm{H}_{2} \mathrm{O}\right)$ [30]. In addition, this desirable composite has the following merits. Firstly, the preparation process is facile and mild. Secondly, CNTs are successfully inserted into the Co-MOF and become an integral component of the Co-MOF framework by acting as struts to link Co-MOF nodes, which not only effectively improve the conductivity but also can sustain the harsh oxidative environment of water oxidation without carbon corrosion. Besides, CNTs are inserted into the Co-MOF and $\mathrm{Co}$ (II) is coordinated with nitrogen atoms, which can protect both of them from peeling off and keep robust for maintaining the stable catalytic reactions. Thirdly, a synergistic catalysis of active centers Co(II), organic ligands and CNTs would enhance the bifunctional electrocatalytic performance. Remarkably, the hybrid exhibits comparable OER and ORR catalytic activity to $\mathrm{RuO}_{2}$-based and Pt-based (20 wt\% $\mathrm{Pt} / \mathrm{C})$ catalysts and superior stability in comparison to many of the highly active cobalt-based catalysts reported to date.

\section{Experimental}




\subsection{Synthesis of Co-MOF}

Co-MOF was prepared as described previously with some modification. $0.84 \mathrm{~g}$ of $\mathrm{Co}\left(\mathrm{NO}_{3}\right)_{2} \cdot 6 \mathrm{H}_{2} \mathrm{O}$ and $0.68 \mathrm{~g}$ of benzimidazole (phIM) were dissolved in $72 \mathrm{~mL}$ of $\mathrm{N}$, $\mathrm{N}$-dimethylformamide (DMF) in a $100 \mathrm{~mL}$ glass vial and sonicated to ensure homogeneity. The vial was heated at $130{ }^{\circ} \mathrm{C}$ in an oven for $36 \mathrm{~h}$ followed by slow cooling to room temperature. The purple crystal were collected via filtration and washed with DMF several times and dried under vacuum.

\subsection{Synthesis of (CNTs X wt\%) Co-MOF}

$\mathrm{Co}\left(\mathrm{NO}_{3}\right)_{2} \cdot 6 \mathrm{H}_{2} \mathrm{O}(0.210 \mathrm{~g})$ and phIM $(0.170 \mathrm{~g})$ were dissolved with DMF $(72 \mathrm{~mL})$ in a $100 \mathrm{~mL}$ glass vial. Different amounts of CNTs $(1,5,10,15$ and $20 \mathrm{wt} \%$ : based on the total mass of starting solid materials) were added to the mixtures. After sonication of the solution, the vessel was sealed and heated up to $130{ }^{\circ} \mathrm{C}$ in an oven for $48 \mathrm{~h}$ followed by slow cooling to room temperature. The purple-grayish crystals were collected filtrated and washed with ample DMF and dried under vacuum.

\subsection{Characterizations}

A FEI-TECNAI $\mathrm{G}^{2}$ transmission electron microscope operating at $200 \mathrm{kV}$ (FEI company) was used to make the transmission electron microscopy (TEM) images, high-angle annular dark-field scanning transmission electron microscope (HAADF-STEM), high resolution TEM images (HRTEM) and element analysis mapping. Elemental composition data was collected by energy dispersive X-ray spectroscopy (EDS) performed using a TECNAI $\mathrm{G}^{2}$ microscope. X-ray diffraction (XRD) measurement was performed on a Rigaku D/max-2400 diffractometer, using 
$\mathrm{CuK} \alpha$ radiation as the $\mathrm{X}$-ray source in the $2 \theta$ range of $10^{\circ}-80^{\circ} . \mathrm{X}$-ray photoelectron spectroscopy (XPS) was recorded on a PHI-5702 instrument and the $\mathrm{C}_{1 \mathrm{~s}}$ line at 291.4 $\mathrm{eV}$ was used as the binding energy reference. Scanning electron microscopy (SEM) samples were prepared by drop-drying the aqueous suspensions onto the copper substrate, and SEM analysis was performed by using an MIRA 3 XMU scanning electron microscope. Fourier transform infrared (FT-IR) spectroscopy of the sample was recorded with BRUKER VERTEX 70 FT-IR spectrometer (America Bruker Corporation) with a $\mathrm{KBr}$ plate. Thermogravimetric analysis (TGA) was performed on a PerkinElmer TG Analyzer.

\subsection{Electrochemical measurements}

All the electrochemical measurements were carried out in a electrochemical cell $(\mathrm{V}=15 \mathrm{~mL})$ at room temperature using a three-electrode system with glassy carbon electrode (GCE, diameter: $3.0 \mathrm{~mm}$ ) as working electrode, Pt wire as counter electrode, and $3 \mathrm{M} \mathrm{KCl}-\mathrm{Ag} / \mathrm{AgCl}$ as reference electrode. Electrochemical Impedance Spectroscopy (EIS) experiment was performed on a VMP2 Multi-potentiostat (Princeton Applied Research, USA), controlled by EC-Lab (V9.24) software (Bio-LogicSA). The measurements were carried out in a $0.1 \mathrm{~mol} \mathrm{~L}^{-1}$ or $1.0 \mathrm{~mol} \mathrm{~L}^{-1}$ $\mathrm{KOH}$ aqueous electrolyte at room temperature. Prior to use, the working electrode was polished mechanically with $\mathrm{Al}_{2} \mathrm{O}_{3}$ powders (Aldrich, $0.05 \mathrm{~mm}$ ) to obtain a mirror-like surface and then washed with deionized water and ethanol and allowed to dry. Then, $5 \mathrm{mg}$ of catalyst and $200 \mu \mathrm{L}$ of $0.5 \mathrm{wt} \%$ Nafion solution were dispersed in $1 \mathrm{~mL}$ of $1: 1 \mathrm{v} / \mathrm{v}$ water/ethanol mixed solvent with at least 30 min sonication to form a 
homogeneous ink. Then $5 \mu \mathrm{L}$ of the catalyst ink (containing $20.8 \mu \mathrm{g}$ of catalyst) was loaded onto glassy carbon electrode (loading $297 \mu \mathrm{g} \mathrm{cm}^{-2}$ ). The electrode was allowed to dry at room temperature before measurement. The working electrodes were scanned for several times until the signals were stabilized and then the data were collected. The OER activities of all the samples were investigated by the linear sweep voltammograms (LSVs) method at the scan rate of $5 \mathrm{mV} \mathrm{s}^{-1}$ in $1.0 \mathrm{~mol} \mathrm{~L}^{-1} \mathrm{KOH}$. The durability test for OER was performed on the catalysts by cycling the electrode potential between 1.0 and $1.8 \mathrm{~V}$ at $200 \mathrm{mV} \mathrm{s}^{-1}$ for 1000 cycles, after which the LSVs for the OER was measured. All the potentials reported in this study were all quoted against the Reversible Hydrogen Electrode (RHE) using eqn (2).

$$
\begin{aligned}
\mathrm{E}(\mathrm{RHE}) & =\mathrm{E}(\mathrm{SHE})+0.059 \times \mathrm{pH}-\mathrm{IR}_{\Omega} \\
& =\mathrm{E}(\mathrm{Appl})+\Phi(\mathrm{Ag} / \mathrm{AgCl})+0.059 \times \mathrm{pH}-\mathrm{IR}_{\Omega}
\end{aligned}
$$

Herein, $\mathrm{E}(\mathrm{SHE})$ is the potential versus standard hydrogen electrode (SHE) potential, $\mathrm{E}(\mathrm{Appl})$ is the applied potential vs. $\mathrm{Ag} / \mathrm{AgCl}$ reference, $\Phi(\mathrm{Ag} / \mathrm{AgCl})$ is the electrode potential of the $\mathrm{KCl}$-saturated $\mathrm{Ag} / \mathrm{AgCl}$ reference electrode $(0.205 \mathrm{~V}$ vs. $\mathrm{SHE}$ ), and $\mathrm{R}_{\Omega}$ is the entire resistance containing solution resistance and circuit resistance. All current densities were normalized using the geometrical area of the GC electrode.

As for ORR experiment, a flow of $\mathrm{O}_{2}$ or $\mathrm{N}_{2}$ was maintained over the electrolyte during the recording of electrochemical measurements in order to ensure its continued $\mathrm{O}_{2}$ or $\mathrm{N}_{2}$ saturation. Cyclic voltammograms (CVs), LSVs, and rotating disk electrode (RDE) tests were carried out by using a glassy carbon rotating disk electrode. The 
scan rate of CVs was kept as $50 \mathrm{mV} \mathrm{s}^{-1}$ while $2 \mathrm{mV} \mathrm{s}^{-1}$ for LSVs and RDE tests in a $0.1 \mathrm{~mol} \mathrm{~L}^{-1} \mathrm{KOH}$. The electron transfer number and peroxide yield can also be derived from the results of the rotating ring-disk electrode (RRDE) measurements. The data were recording using a RRDE-3A (ALS Co., Ltd) and the $\mathrm{CH}$ instruments electrochemical workstation ( $\mathrm{CH}$ instrument, Inc. Austin).

The reproducibility of the electrochemical activity of the catalyst for the OER and ORR in alkaline solutions was confirmed by repeating the experiments for at least 3 times.

\section{Results and Discussion}

\subsection{Formation of Co-MOF@CNTs composite}

Our synthetic route for Co-MOF@CNTs was illustrated in Fig.1. The Co-MOF was created by linking $\mathrm{Co}\left(\mathrm{NO}_{3}\right)_{2} \cdot 6 \mathrm{H}_{2} \mathrm{O}$ and phIM. It has an open-framework structure adopting sodalite topology with hexagonal symmetry as illustrated in Fig. 1b. Besides, Co-MOF incorporates nets of corner-sharing tetrahedral $\mathrm{CoN}_{4}$ where $\mathrm{Co}(\mathrm{II})$ centers coordinated by $\mathrm{N}$ atoms in the 1,3-positions of the ring as shown in Fig. 1c. The preparation process of composite was as follows. First, the CNTs served as nucleation centers for loading MOFs [31]. Then, the CNTs were homogeneously dispersed in DMF in the presence of $\mathrm{Co}\left(\mathrm{NO}_{3}\right)_{2} \cdot 6 \mathrm{H}_{2} \mathrm{O}$ and phIM through ultrasonic treatment, and $\mathrm{Co}^{2+}$ adsorbed onto the CNTs due to an electrostatic interaction. Subsequently, the small Co-MOF located on the surface of CNTs and served as crystal nuclei for the growth of Co-MOF polyhedra in the stewing process. Ultimately, the long CNTs were in situ self-inserted into the Co-MOF crystal, abbreviated as Co-MOF@CNTs (X wt\%) 
where $\mathrm{X}$ indicated the weight percent of CNTs added into the composite.

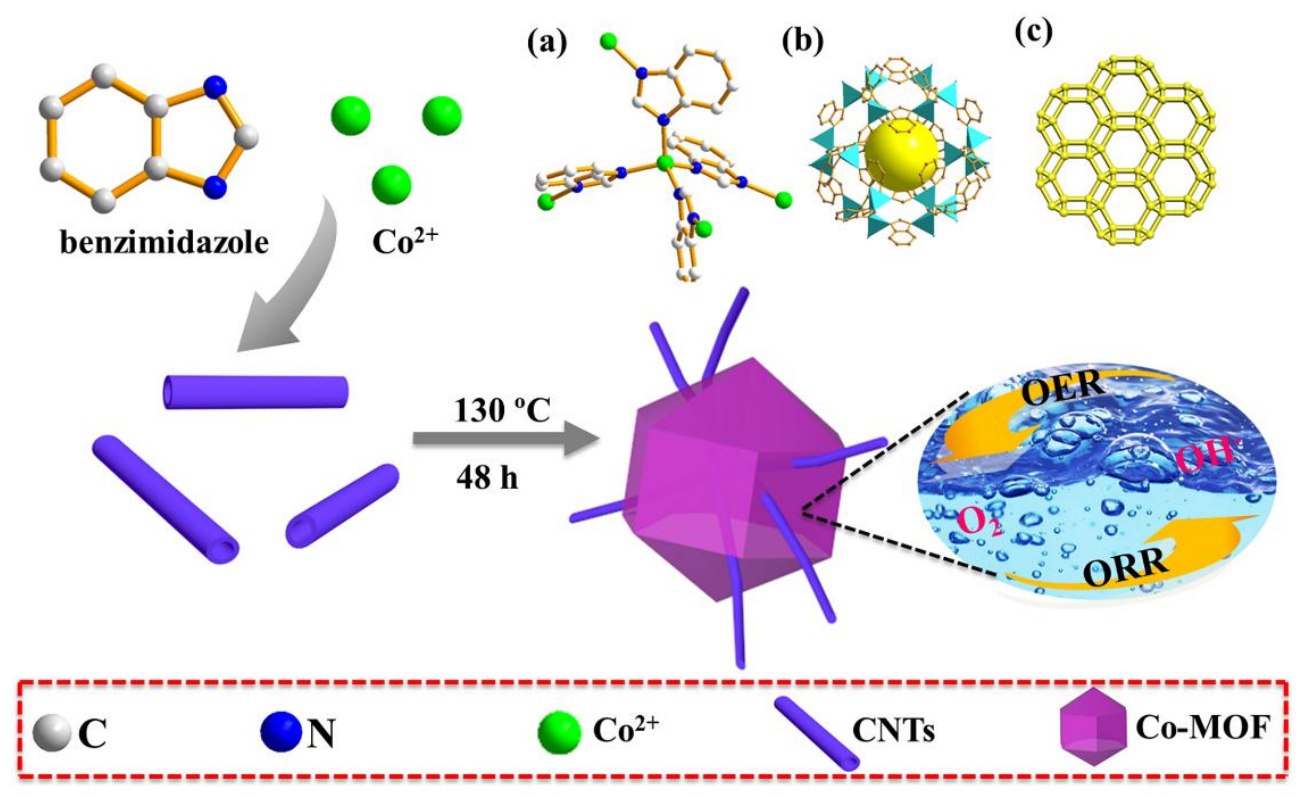

Fig. 1. Synthesis of the catalyst Co-MOF@CNTs.

\subsection{Structure characterizations}

The morphologies and structural features of the CNTs, Co-MOF and Co-MOF@CNTs (5 wt\%) can be observed directly from the TEM. As was shown in Fig.2a, the CNTs were uniformly distributed with a diameter of $20-50 \mathrm{~nm}$. Fig. 2b showed the typical image of Co-MOF, which indicated that a crystalline material was achieved. Fig. 2c and 2d revealed that the Co-MOF@CNTs consisted of uniform CNT-inserted polyhedral with a perfectly smooth surface. The intertwined CNTs were inserted in Co-MOF polyhedral and became an integral component of the Co-MOF framework, forming a novel Co-MOF@CNTs nanocomposite. By contrast, it was obvious to see that the morphological feature of the physical mixed Co-MOF and CNTs (the content of CNTs in Co-MOF+CNTs was 5 wt $\%$, denoted as Co-MOF+CNT) was different from the as-prepared Co-MOF@CNTs (5 wt \%). Fig. 2e indicated that the CNTs were not intertwined with Co-MOF. Noteworthy, the obtained 
product was mainly a simple mixture of Co-MOF crystalline and CNTs. The results proved that the Co-MOF was combined with CNTs instead of simple physical mixing in Co-MOF@CNTs (5 wt\%). From the picture of Fig. 2f, it could be seen that the as-prepared product contained $\mathrm{C}, \mathrm{N}, \mathrm{O}$, and $\mathrm{Co}$.
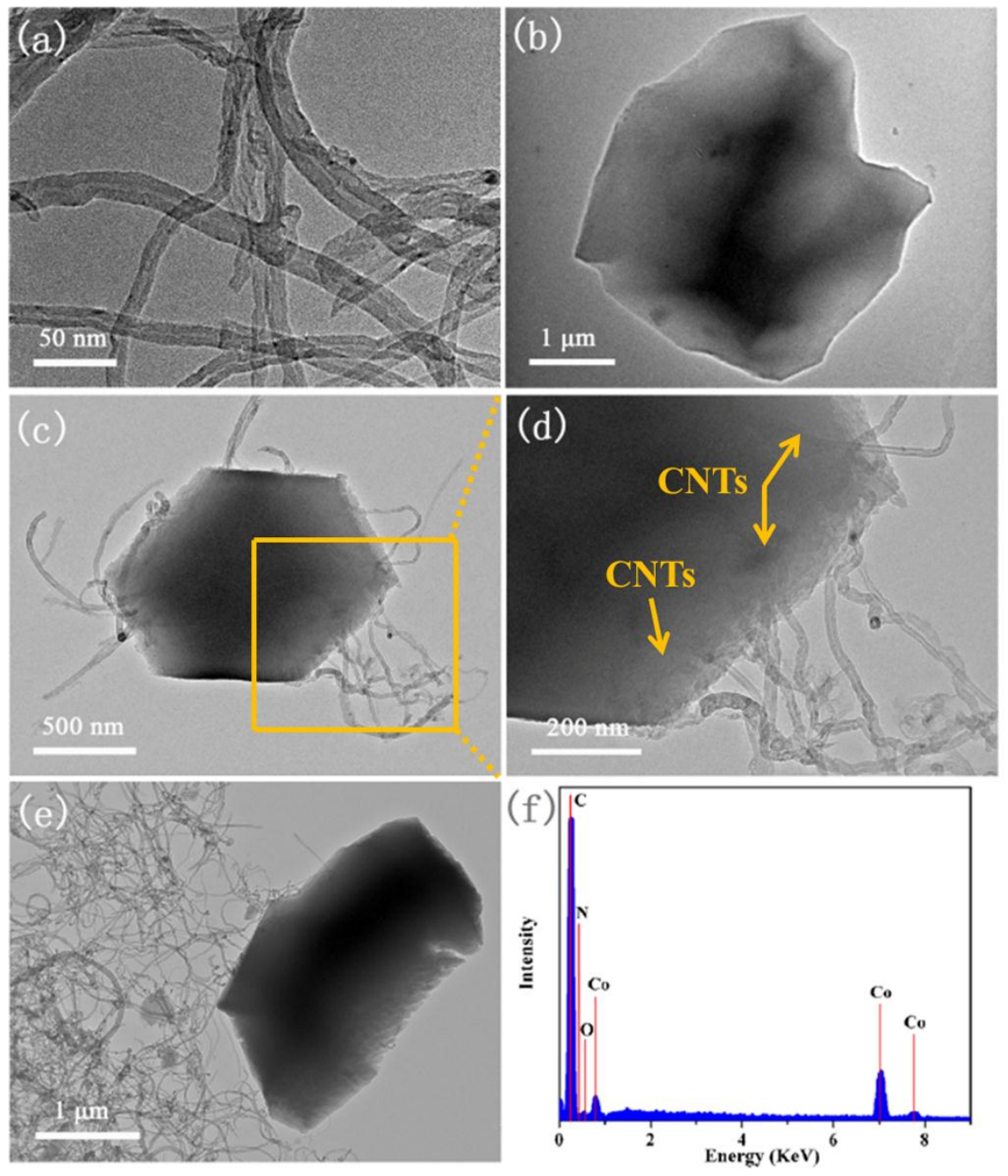

Fig. 2. TEM (a) of CNTs, (b) of Co-MOF, (C) and (d) of Co-MOF@CNTs (5 wt\%), (image $\mathrm{d}$ is a local image of c), (e) of physically mixed Co-MOF+CNTs and EDS spectrum (f) of Co-MOF@CNTs (5wt\%).

To give further insight into the morphology and structure of the as-synthesized composites, SEM analysis has been carried out. Fig. 3a showed the morphology of 
bare-CNTs. Fig. $3 b$ revealed the typical images of the Co-MOF. From Fig. 3c and 3d, it could be seen that CNTs successfully incorporated the Co-MOF inside them without disturbing the synthesis of the MOF. As expected, the Co-MOF was almost bared and not intertwined with CNTs in Co-MOF+CNTs (Fig. 3e). More importantly, as was showed in Fig. 3f, the XRD patterns of Co-MOF and Co-MOF@CNTs (5 wt\%) were found to be in perfect agreement with simulated MOF, confirming that CNTs incorporation did not disturb or destroy the Co-MOF crystal structure. Besides, the characteristic CNTs (002) peak, normally at $2 \theta=26-27^{\circ}$, was almost swamped by high-intensity Co-MOF peaks.
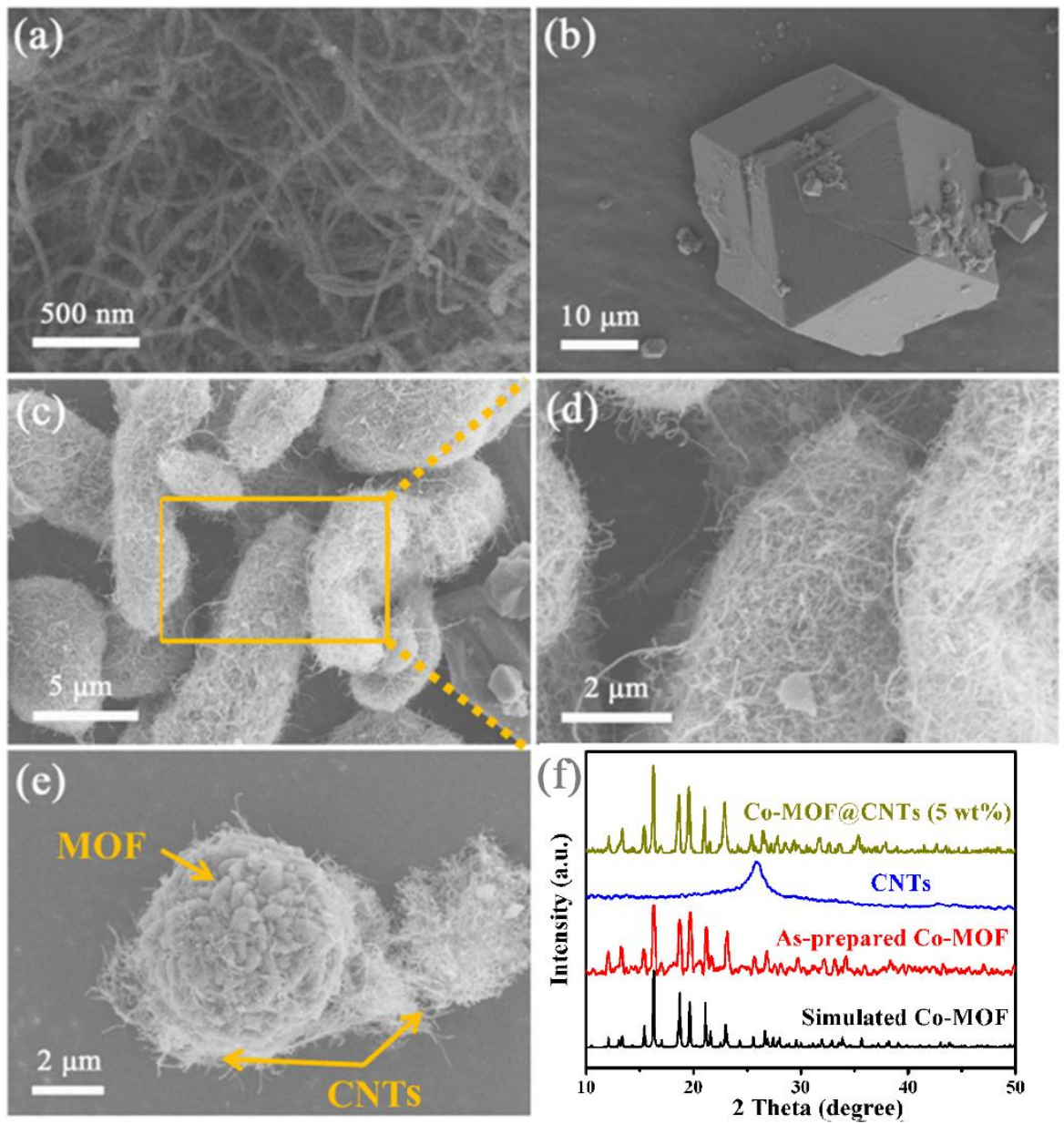

Fig. 3. SEM (a) of CNTs, (b) of Co-MOF, (C) and (d) of Co-MOF@CNTs (5 wt\%), (image $\mathrm{d}$ is a local image of c), (e) of physically mixed Co-MOF+CNTs and 
Wide-angle XRD patterns (f) of simulated Co-MOF, as-prepared Co-MOF, CNTs and Co-MOF@CNTs (5 wt \%).

Additionally, to investigate each element's distribution in the Co-MOF@CNTs (5 wt\%) further, SEM image and the corresponding EDS mapping images were presented (Fig. 4). The results demonstrated the homogenous distribution of C, Co, N and $\mathrm{O}$ elements.
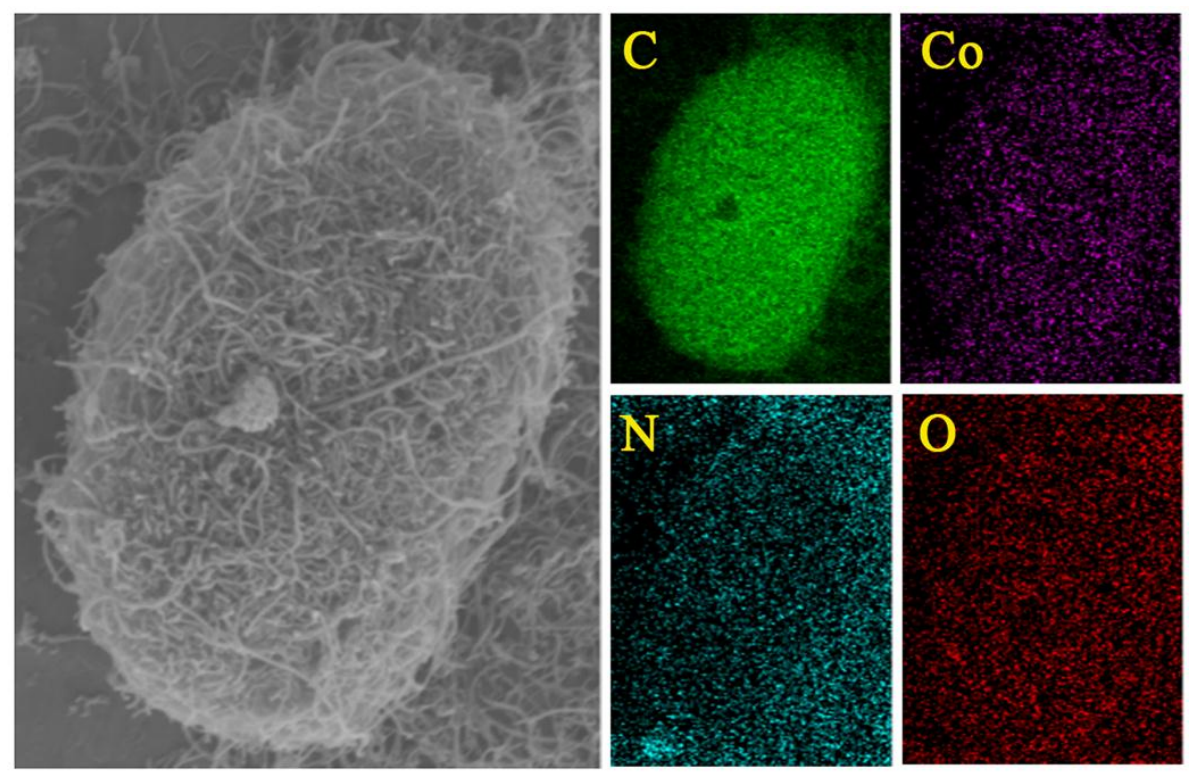

Fig. 4. SEM image of of Co-MOF@CNTs (5 wt \%) and EDS mapping results of the elements $\mathrm{C}, \mathrm{Co}, \mathrm{N}$ and $\mathrm{O}$ for the boxed area.

The chemical composition of the obtained Co-MOF@CNTs (5 wt $\%$ ) nanomaterial was detected from the XPS spectra. As expected, the XPS survey spectrum given in Fig. 5a showed the Co 2p, N 1s, O 1s and C 1s peaks in Co-MOF@CNTs (5 wt\%). The deconvolution of the Co 2p peak in Co-MOF@CNTs (5 wt $\%)$ and Co-MOF showed four peaks (Fig. 5b). The peak at $781.5 \mathrm{eV}$ was from Co $2 \mathrm{p}_{3 / 2}$, while the peak at $797.7 \mathrm{eV}$ was caused by Co $2 \mathrm{p}_{1 / 2}$. The satellite peak at around $786.6 \mathrm{eV}$ and 803.6 $\mathrm{eV}$ were two shake-up type peaks of Co at the high binding energy side of the Co 
$2 p_{3 / 2}$ and Co $2 p_{1 / 2}$ edge. The presence of Co $2 p_{3 / 2}$ and Co $2 p_{1 / 2}$ main peaks and shake-up satellite peaks indicated the presence of $\mathrm{Co}^{2+}$ in the high-spin state [32]. The comparison of Co 2p spectra in Co-MOF@ CNTs (5 wt \%) and Co-MOF had a positive shift in the binding energy of the peaks. This implied the closely assembly and interaction between Co-MOF and CNTs, resulting in the impaired electron density of Co in Co-MOF [22].
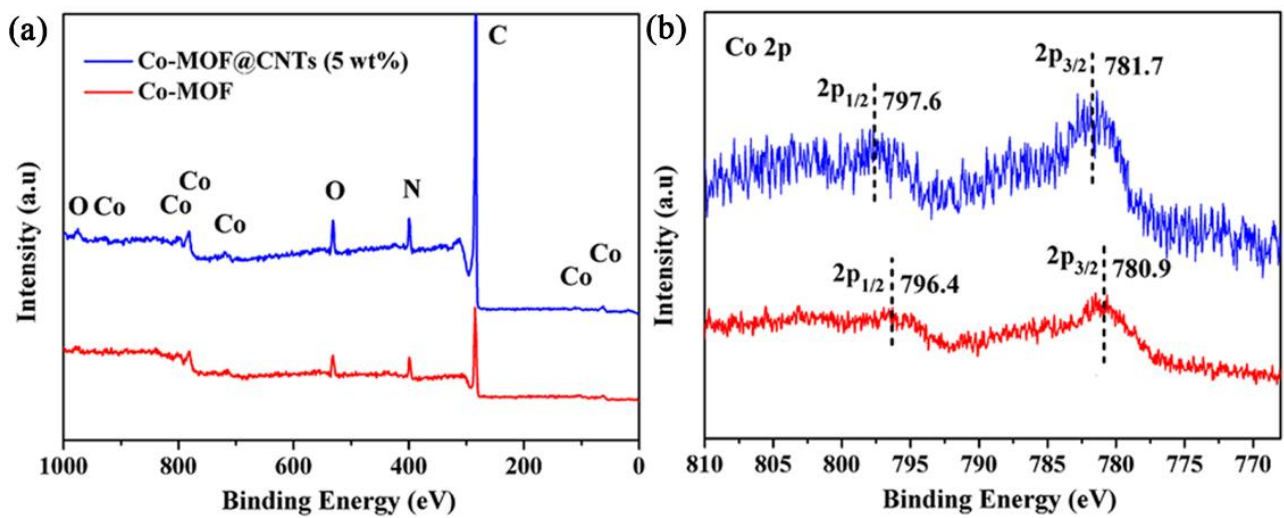

Fig. 5. (a) XPS wide-scan spectrum of the Co-MOF and Co-MOF@CNTs (5wt\%) and (b) Co 2p spectrum of Co-MOF and Co-MOF@CNTs (5 wt $\%$ ).

Meanwhile, comparison between the FT-IR spectra of Co-MOF@CNTs, Co-MOF and benzimidazole revealed a significant difference (Fig. S1). For benzimidazole, the aromatic C-H stretching vibrations were observed near $3100-3000 \mathrm{~cm}^{-1}$. The stretch band of $\mathrm{C}=\mathrm{C}$ double bond of aromatic ring absorbed near $1600-1500 \mathrm{~cm}^{-1}$. And the stretch band of N-H group absorbed strongly at 3500-2500 $\mathrm{cm}^{-1}$, and this band was accompanied by bend vibration of $\mathrm{N}-\mathrm{H}$ group at $1588 \mathrm{~cm}^{-1}$ and $628 \mathrm{~cm}^{-1}$. The peaks at $1620 \mathrm{~cm}^{-1}$ may be assigned to $\mathrm{C}=\mathrm{N}$ stretching vibrations. The sharp peaks at 1478 $\mathrm{cm}^{-1}, 1454 \mathrm{~cm}^{-1}$ and $1405 \mathrm{~cm}^{-1}$ could be assigned to the ring vibrations. The $\mathrm{C}-\mathrm{N}$ stretching vibrations were observed to produce intense bands between 1198 and 1307 
$\mathrm{cm}^{-1}$. Whereas for the Co-MOF and Co-MOF@CNTs, the disappearance of broad $\mathrm{N}-\mathrm{H}$ stretching bands between $3250-2500 \mathrm{~cm}^{-1}$ and $\mathrm{N}-\mathrm{H}$ bending bands at $1588 \mathrm{~cm}^{-1}$ and $628 \mathrm{~cm}^{-1}$ revealed that the benzimidazole linkers were fully deprotonated during the formation of the Co-MOF and Co-MOF@ CNTs structure [33]. The stability of the synthesized Co-MOF@CNTs (5 wt \%), Co-MOF and CNTs was examined by thermal analysis (Fig. S2). The synthesized Co-MOF and Co-MOF@CNTs (5 wt\%) showed an excellent thermal stability up to $500{ }^{\circ} \mathrm{C}$. The weight loss before $200{ }^{\circ} \mathrm{C}$ was caused by the volatilization of water molecules trapped inside the porosities. Besides, it was found that the Co-MOF@CNTs (5 wt $\%$ ), Co-MOF and CNTs afforded Langmuir surface areas of $970 \mathrm{~m}^{2} \mathrm{~g}^{-1}, 1109 \mathrm{~m}^{2} \mathrm{~g}^{-1}$, and $117 \mathrm{~m}^{2} \mathrm{~g}^{-1}$, respectively. The large surface areas of the 3D hierarchical structure enabled the Co-MOF@CNTs (5wt\%) as a superior oxygen catalyst.

\subsection{Oxygen evolution activity}

The OER electrocatalytic behaviour of the hybrid samples were examined by linear scan voltammetry (LSV) curves in $\mathrm{O}_{2}$-saturated 1.0 M KOH. As shown in Fig. 6a, CNTs exhibited weak activity over the whole window of applied potentials, indicating the inactive nature of bare CNTs towards $\mathrm{O}_{2}$ evolution. Note that MOF alone had little catalytic activity for OER, whereas CNTs-based MOF exhibited high catalytic activity. By tuning the ratio of CNTs to MOF, Co-MOF@CNTs (5 wt $\%$ ) exhibited the earliest onset potential at $1.51 \mathrm{~V}$ vs. RHE (all potentials reported thereafter were quoted against RHE for comparison purposes) and manifested a current density of $10 \mathrm{~mA}$ $\mathrm{cm}^{-2}$ at the overpotential as low as $0.34 \mathrm{~V}$ among Co-MOF@CNTs (1 wt $\%$ ), 
Co-MOF@CNTs (5 wt\%), Co-MOF@CNTs (10 wt\%) and Co-MOF@CNTs (15 wt\%), indicating the lowest-energy input for driving OER. The result proved the CNTs played an important role in OER by influencing the electron-conductive property in the obtained hybrid materials. But excess CNTs would reduce the ratio of active site in the hybrid material and suppress the catalytic activity for OER.

In electrochemical catalysis, the electrical conductivity of catalysts is very important. In our work, we introduced CNTs as conductive substrates to improve the poor conductivity of active sites Co-MOF. However, pure CNTs themselves exhibited negligible OER activity (Fig. 6a). Thus, conductive substrates CNTs and active sites Co-MOF existed as contradictory parts: the more weight percentages of conductive substrates CNTs meant the less content of active constituent Co-MOF in the nanocomposites. As shown in Fig. S3, the over-potentials (at $10 \mathrm{~mA} \mathrm{~cm}{ }^{-2}$, red curve) showed an inverted "volcano"-type relationship versus weight percentages of CNTs with the order Co-MOF@CNTs $(5$ wt $\%)<$ Co-MOF@CNTs $(1$ wt $\%)<$ Co-MOF@CNTs $(10$ wt $\%)<$ Co-MOF@CNTs $(15$ wt $\%)<$ Co-MOF, indicating that Co-MOF@CNTs (5 wt $\%$ ) had the lowest-energy input for driving OER. The result showed that the different weight percentages of CNTs would result in different OER performance. Only at an appropriate value of the weight percentages, the nanocomposites exhibited the optimal OER performance.

SEM was carried out to see that the difference in the morphology of the nanocomposites with increasing concentration of CNTs incorporated in the Co-MOF. As shown in Fig. S4, Co-MOF was not always tightly combined with the CNTs. Only 
at appropriate ratio (below $5 \%$ ), CNTs could be incorporated inside the Co-MOF (Fig. S4a, b). Further increasing the weight percentages of CNTs would result in redundant and bare CNTs (Fig. S4c, d). During the OER measurement, the mass of catalyst loadings was kept constant $\left(297 \mu \mathrm{g} \mathrm{cm}^{-2}\right)$. The more weight percentages of CNTs meant the less content of active constituent Co-MOF in the nanocomposites. This might explain the reason why excess CNTs would reduce the ratio of active site in the hybrid material and suppress the catalytic activity for OER.

In addition, based on the polarization curves, the corresponding Tafel plots were constructed (Fig. 6b). An important parameter to evaluate the activity in OER is the Tafel slope $b$, which is determined by fitting polarization data to the Tafel equation ( $\eta$ $=\mathrm{a}+$ blog $|\mathrm{J}|$, where $\eta$ is the overpotential, $\mathrm{b}$ is the Tafel slope, and, $\mathrm{J}$ is the current density). A smaller Tafel slope means a faster increase of OER rate with the increasing potential. The Tafel slope of Co-MOF@CNTs (5 wt $\%$ ) was $69 \mathrm{mV} \mathrm{dec}{ }^{-1}$, which was lower than Co-MOF@CNTs $\left(1 \mathrm{wt} \%, 79 \mathrm{mV} \mathrm{dec}{ }^{-1}\right)$, Co-MOF@CNTs $(10 \mathrm{wt} \%, 82$ $\left.\mathrm{mV} \mathrm{dec}{ }^{-1}\right)$, Co-MOF@CNTs $\left(15 \mathrm{wt} \%, 97 \mathrm{mV} \mathrm{dec}^{-1}\right) \mathrm{MOF}\left(125 \mathrm{mV} \mathrm{dec}{ }^{-1}\right)$ and CNTs (256 mV dec $\left.{ }^{-1}\right)$. It indicated that Co-MOF@CNTs (5 wt $\%$ ) displayed the best activity among them. A detailed comparison of different highly active Co-based OER catalysts was shown (Table S1, Supporting information), further confirming the outstanding catalytic behaviour of Co-MOF@CNTs (5 wt \%).

Strong durability toward OER is critical for electrocatalysts in future energy conversion and storage systems. A $25 \mathrm{~h}$ chronopotentiometry test has been conducted at different current densities. As shown in Figure 6c, the Co-MOF@CNTs (5 wt\%) 
had nearly constant operating potentials of 1.577 and $1.610 \mathrm{~V}$ at current densities of 10 and $20 \mathrm{~mA} \mathrm{~cm}{ }^{-2}$, respectively. There was no significant change in the operating potential after $25 \mathrm{~h}$ of test. Even generating a large current of $40 \mathrm{~mA} \mathrm{~cm}$, Co-MOF@CNTs (5 wt \%) uncovered good durability and demonstrated a stable potential of $1.649 \mathrm{~V}$ with only increased by a few millivolts after $25 \mathrm{~h}$ testing. Furthermore, we also probed the durability of the Co-MOF@CNTs (5 wt $\%$ ) under continuous potential scanning conditions. As revealed in Figure 6d, the hybrid afforded a good stability with negligible current loss for 1000 cycles at a scan rate of $5 \mathrm{mV} \mathrm{s}^{-1}$, demonstrating the superior durability of Co-MOF@CNTs (5 wt $\%$ ) in alkaline solution. It was noted that the morphology of Co-MOF@CNTs (5\%) was well retained after long-term stability test, as demonstrated by the SEM images (see comparison in Fig. 3c and the inset in Fig. 6d). We reasonably believed these observations resulted from the unique frame architecture, that was, Co(II) centers were firmly confined to $\mathrm{N}$ atoms and CNTs were closely inserted into the Co-MOF. Besides, CNTs can sustain the harsh oxidative environment of water oxidation without carbon corrosion. This novel freestanding 3D structure provided not only a synergistic catalysis of inorganic catalysts and ligands, but also high conductivity and steady, which was thus beneficial to OER activity and durability. 

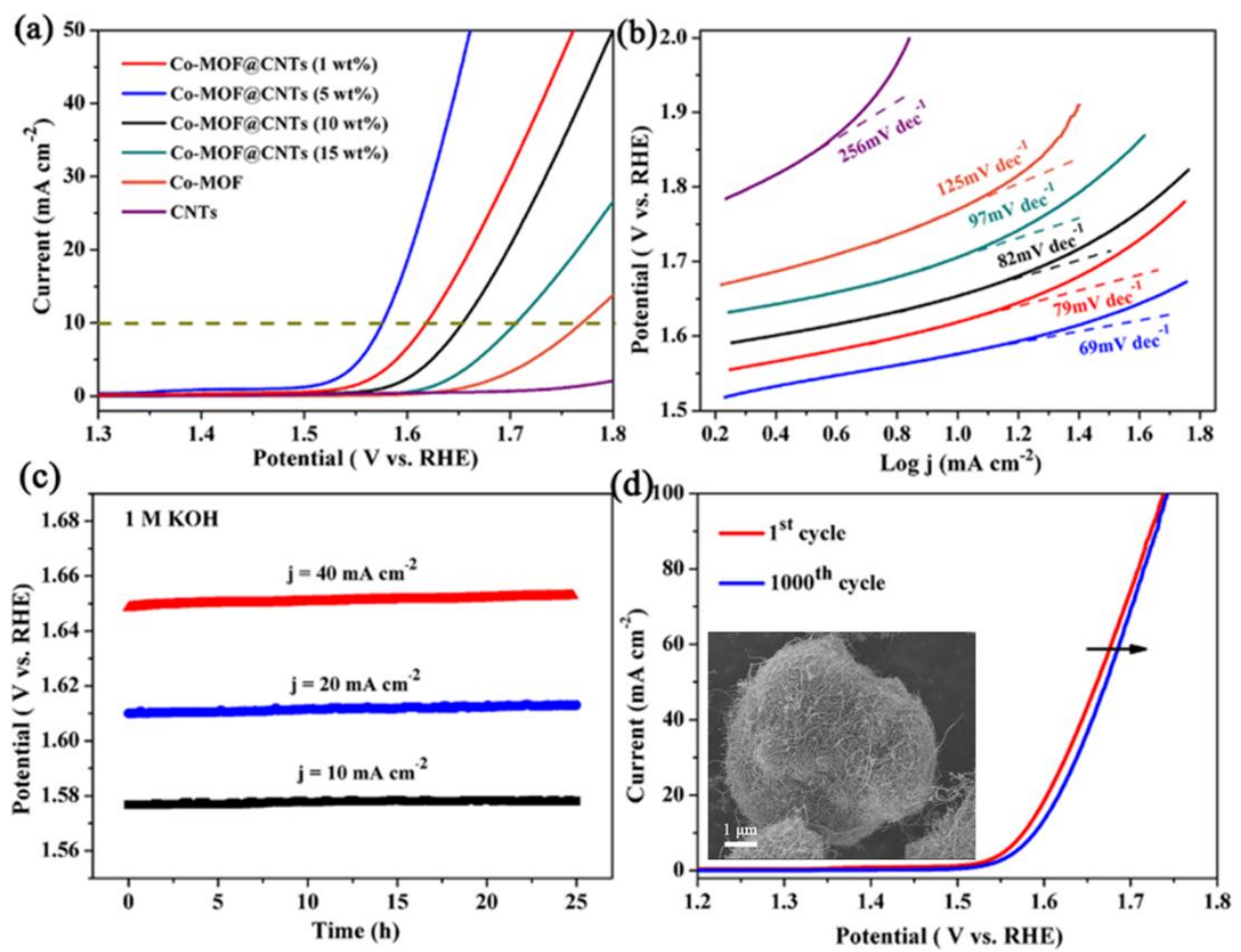

Fig. 6. (a) Polarization curves of CNTs, Co-MOF, Co-MOF@CNTs (15 wt\%), Co-MOF@CNTs (10wt\%), Co-MOF@CNTs (5 wt \%) and Co-MOF@CNTs (1 wt\%) in an $\mathrm{O}_{2}$-saturated $1.0 \mathrm{M} \mathrm{KOH}$ solution (scan rate $5 \mathrm{mV} \mathrm{s}^{-1}$ ). (b) Tafel plots of catalysts. (c) Chronopotentiometry curves of Co-MOF@CNTs (5 wt \%) at different current densities of 10,20 , and $40 \mathrm{~mA} \mathrm{~cm}^{-2}$. (d) Durability test for the Co-MOF@CNTs (5 wt\%) after 1000 cycles (inset: TEM of the Co-MOF@CNTs (5 wt\%) after the stability test).

We also evaluated the electrochemically active surface area $\left(\mathrm{A}_{\text {echem}}\right)$ using a simple cyclic voltammetry $(\mathrm{CV})$ method. Because there is a positive correlation between the value of electrochemical double-layer capacitance $\left(\mathrm{C}_{\mathrm{dl}}\right)$ and the product of $\mathrm{A}_{\mathrm{echem}}$ and the scan rate $(v)$, namely $\mathrm{Cdl} \propto v \times \mathrm{A}_{\text {echem, }} \mathrm{A}_{\text {echem }}$ can be calculated from $\mathrm{C}_{\mathrm{dl}}$ of the catalytic surface, and linear relationship can be utilized to estimate $\mathrm{C}_{\mathrm{dl}}$ via the slope [34-37]. Current response in the potential window used for the CV (1.35-1.40 V vs. 
RHE) at different scan rates $\left(2-10 \mathrm{mV} \mathrm{s}^{-1}\right)$ should be due only to the charging of the double-layer (Fig. S5a, b and c). By calculating the slope from the linear relationship of the current density against the scan rate, $\mathrm{C}_{\mathrm{dl}}$ of Co-MOF@CNTs (5 wt $\%$ ) was confirmed to be $22.31 \mathrm{mF} \mathrm{cm} \mathrm{cm}^{-2}$, which was about 2.5 and 6.2 times larger as compared to the Co-MOF $\left(6.24 \mathrm{mF} \mathrm{cm}^{-2}\right)$ and CNTs $\left(3.06 \mathrm{mF} \mathrm{cm}^{-2}\right)$ (Fig. S5d). Since $C_{d l}$ was proportional to the active surface area of electrocatalysts $[38,39]$, the results demonstrated that the CNTs were effective in enlarging the active surface area. Therefore, the superior OER activity of Co-MOF@CNTs (5 wt $\%)$ was closely related to CNTs would effectively improve the transportation of the electrons and help the permeation and flow of the electrolyte in the electrode, which was similar to the water channels in the paddy.

In order to verify that the direct growth of Co-MOF on the conductive CNTs could greatly enhance the electron transport, the electrochemical impedance spectroscopy (EIS) measurements were carried out on GCE, Co-MOF and Co-MOF@CNT (5 wt\%) by applying an $\mathrm{AC}$ voltage with $5 \mathrm{mV}$ amplitude in a frequency range from 100,000 to $0.1 \mathrm{~Hz}$ and recorded at an open circuit potential in $5.0 \mathrm{mM} \mathrm{K}_{3} \mathrm{Fe}(\mathrm{CN})_{6} / \mathrm{K}_{4} \mathrm{Fe}(\mathrm{CN})_{6}$ (1:1) solution containing $0.1 \mathrm{M} \mathrm{KCl}$. As shown in Fig. 7a, the intercept of the plot at the real axis provided the equivalent series resistance (ESR). In addition, the different diameters of the semicircle shown in the high-frequency range presented the changeable charge transfer resistance (Rct) in the electrochemical system. Examination of Fig. 7a showed a significant decrease of Rct for Co-MOF@CNTs (5 wt $\%$ ) than Co-MOF, which indicated that the inserted CNTs could boost the electronic 
conductivity and enable much easier charge transfer at the electrode/electrolyte interface. As shown in Fig. $7 \mathrm{~b}$, the impedance data were obtained by fitted to the $\mathrm{R}(\mathrm{C}(\mathrm{RW})$ ) equivalent circuit model using the ZsimpWin program (Princeton Applied Research). The impedance data obtained contain the electron transfer $R$ ct and the diffusion process (modeled as the Warburg-type impedance, W). Correspondingly, the Bode plots show the information of impedance, frequency and phase angle. Fig. 7c and $\mathrm{d}$ were the Bode plots for the data in Fig. 7a. The axes of both impedance modulus $|\mathrm{Z}|$ and frequency (f) were logarithmic. The impedance of the system measured in the low frequency range is closely related to the polarization resistance (or Rct) [40]. As can be seen, the impedance at low-frequency range $\left(10^{-1} \mathrm{~Hz}\right)$ increased in the order Co-MOF@CNTs $(5 \%)<$ GCE $<$ Co-MOF, which in accordance with the Nyquist plots. In Fig. 7d, Bode plots exhibited a time constant at high frequency of three samples, which corresponding to the charge transfers controlled processes. And the peak of the Co-MOF@CNTs (5\%) shifted to a significantly higher frequency (compared to the GCE and Co-MOF). Thus, the improved electronic conductivity was considered to be a key factor in improving the electrochemical performance of Co-MOF. 

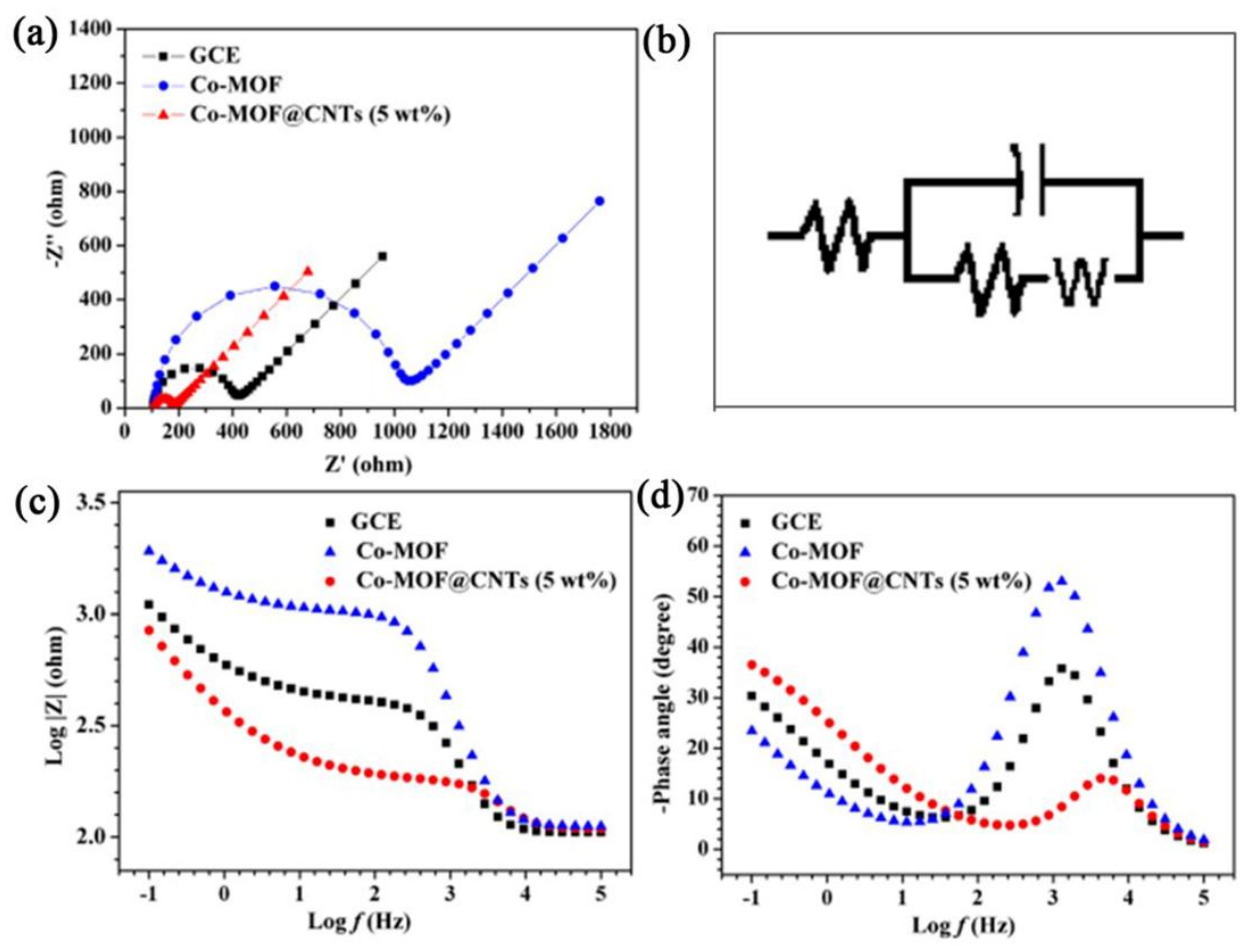

Fig. 7. (a) Nyquist diagrams of EIS for GCE, Co-MOF and Co-MOF@CNTs (5 wt\%) in $5.0 \mathrm{mM} \mathrm{K}{ }_{3} \mathrm{Fe}(\mathrm{CN})_{6} / \mathrm{K}_{4} \mathrm{Fe}(\mathrm{CN})_{6}(1: 1)$ solution containing $0.1 \mathrm{M} \mathrm{KCl}$. (b) equivalent circuit. (c) and (d) EIS Bode plots for GCE, Co-MOF and Co-MOF@CNTs (5 wt\%).

Besides, the activity of Co-MOF+CNTs toward the OER was also investigated (Fig. S6a). The physical mixture exhibited an onset potential of $1.60 \mathrm{~V}$ and a current density of $10 \mathrm{~mA} \mathrm{~cm}^{-2}$ at $1.70 \mathrm{~V}$, which were inferior to those of the OER catalytic activity of Co-MOF@CNTs (5 wt\%). Moreover, the higher Tafel slope of physical mixture $\left(101 \mathrm{mV} \mathrm{dec}^{-1}\right)$ than that of Co-MOF@CNTs $(5 \mathrm{wt} \%)\left(69 \mathrm{mV} \mathrm{dec}^{-1}\right)$ revealed the low activity of physical mixture (inset in Fig. S6a). The $\mathrm{C}_{\mathrm{dl}}$ of Co-MOF+CNTs (9.41 $\mathrm{mF} \mathrm{cm}^{-2}$ ) was lower than that of Co-MOF@CNTs (5 wt\%) (Fig. S6b).

The durability test of Co-MOF and Co-MOF+CNTs was also carried out by means of a chronopotentiometry measurement (Fig. S7). As expected, the Co-MOF exhibited good stability but had higher over-potential than Co-MOF@CNTs (5 wt\%). By 
contrast, the over-potential of Co-MOF+CNTs was high and grown quickly after about $15 \mathrm{~h}$. Its inferior durability might be because of the detachment of the CNTs during OER process.

In addition, the OER catalytic activity of Co-MOF@CNTs (5 wt \%) was assessed in $1 \mathrm{M} \mathrm{KOH}$ in an anodic direction together with $\mathrm{RuO}_{2}$ for comparison. As shown in Fig. S8a, the $\mathrm{RuO}_{2}$ catalyzed OER with an onset potential of $1.38 \mathrm{~V}$ and over-potential of $0.13 \mathrm{~V}$ to achieve a stable current density of $10 \mathrm{~mA} \mathrm{~cm}{ }^{-2}$. Besides, the Co-MOF@CNTs (5 wt $\%$ ) approached a large current density of $57 \mathrm{~mA} \mathrm{~cm}^{-2}$ at an over-potential of $0.44 \mathrm{~V}$, which was similar to that of $\mathrm{RuO}_{2}$ references. As also observed, the Tafel slope value for the Co-MOF@CNTs (5 wt $\%)\left(69 \mathrm{mV} \mathrm{dec}^{-1}\right)$ was much lower than that of $\mathrm{RuO}_{2}\left(89 \mathrm{mV} \mathrm{dec}{ }^{-1}\right)$, which confirmed a faster increase of OER rate with the increasing potential (inset in Fig. S8a). Furthermore, although $\mathrm{RuO}_{2}$ had small onset overpotential for OER, it was not stable in alkaline solution and its over-potential grew quickly during the chronopotentiometry measurement (Fig. S8b).

\subsection{Oxygen reduction activity}

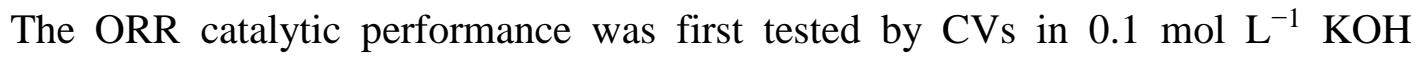
solution saturated with $\mathrm{N}_{2}$ or $\mathrm{O}_{2}$ at a scan rate of $50 \mathrm{mV} \mathrm{s}^{-1}$. As is shown in Fig. 8a, in $\mathrm{N}_{2}$-saturated solution, the Co-MOF@CNTs (5\%) delivered featureless voltammetric current curves between 0.077 and 1.077 V. In contrast, it demonstrated well-defined cathodic peaks for the $\mathrm{O}_{2}$ reduction when the electrolyte solution was saturated with $\mathrm{O}_{2}$. And the MOF-CNTs (5 wt $\%$ ) showed a pronounced cathodic peak for the ORR at 


\section{$0.81 \mathrm{~V}$.}

Figure $8 \mathrm{~b}$ displayed the typical ORR polarization curves at rotating rate of 1600 rpm (round per minute). Compared to the CNTs and Co-MOF, the Co-MOF@CNTs (5\%) excatalyst exhibited higher activity, in terms of higher onset and half-wave potentials. The Co-MOF@CNTs (5\%) sample showed an onset potential of $0.91 \mathrm{~V}$ and a half-wave potential of $0.82 \mathrm{~V}$. For comparison, commercial $20 \mathrm{wt} \% \mathrm{Pt} / \mathrm{C}$ was also examined. The half-wave potential at $1600 \mathrm{rpm}$ was $0.86 \mathrm{~V}$ (Fig. 8b and Fig. S9). The catalytic performance of Co-MOF+CNTs, was much inferior (Fig. S10).

To obtain insight into the electron transfer kinetics of MOF@CNTs (5\%), CNTs, MOF and Co-MOF+CNTs physical mixture during the ORR, we studied the reaction kinetics by rotating-disk voltammetry. The voltammetric profiles in $\mathrm{O}_{2}$-saturated 0.1 $\mathrm{M} \mathrm{KOH}$ showed that the current density was enhanced by an increase in the rotation rate from 300 to $2500 \mathrm{rpm}$ (Figure 8c). The corresponding Koutecky-Levich plots $\left(J^{-1}\right.$ vs $\omega^{-1 / 2}$ ) at various electrode potentials show good linearity (Figure8d). Linearity and parallelism of the plots are considered as typical of first-order reaction kinetics with respect to the concentration of dissolved $\mathrm{O}_{2}$. The kinetic parameters can be analyzed on the basis of the Koutecky - Levich equations:

$$
\begin{aligned}
& \frac{1}{J}=\frac{1}{J_{K}}+\frac{J}{J_{L}}=\frac{1}{J_{K}}+\frac{1}{B \omega^{\frac{1}{2}}} \\
& \mathrm{~B}=0.62 \mathrm{nFC} C_{0} D_{0}^{\frac{2}{3}} V^{\frac{1}{6}} \\
& J_{K}=n F K C_{0}
\end{aligned}
$$

Here $J$ represents the measured current, $J_{\mathrm{K}}$ and $J_{\mathrm{L}}$ are the kinetic and diffusion-limiting current densities, and $\omega$ is the electrode rotating speed in $\operatorname{rad~s}^{-1}, \mathrm{n}$ 
is the overall number of electrons transferred in oxygen reduction, $\mathrm{F}$ is the Faraday constant $\left(\mathrm{F}=96485 \mathrm{C} \mathrm{mol}^{-1}\right), \mathrm{C}_{0}$ is the bulk concentration of $\mathrm{O}_{2}$ in $0.1 \mathrm{M} \mathrm{KOH}(1.2 \times$ $\left.10^{-3} \mathrm{~mol} \mathrm{~L}^{-1}\right), \mathrm{D}_{0}$ is the oxygen diffusion coefficient in $0.1 \mathrm{M} \mathrm{KOH}\left(\mathrm{D}_{0}=1.9 \times 10^{-5}\right.$ $\left.\mathrm{cm}^{2} \mathrm{~s}^{-1}\right), v$ is the kinematic viscosity of the electrolyte $\left(v=0.01 \mathrm{~cm}^{2} \mathrm{~s}^{-1}\right)$, and $\mathrm{k}$ is the electron transfer rate constant. The electron transfer number (n) was calculated to be $\sim 3.7$ at $0.2-0.7 \mathrm{~V}$ from the slopes of Koutecky - Levich plots (Fig. 8d).
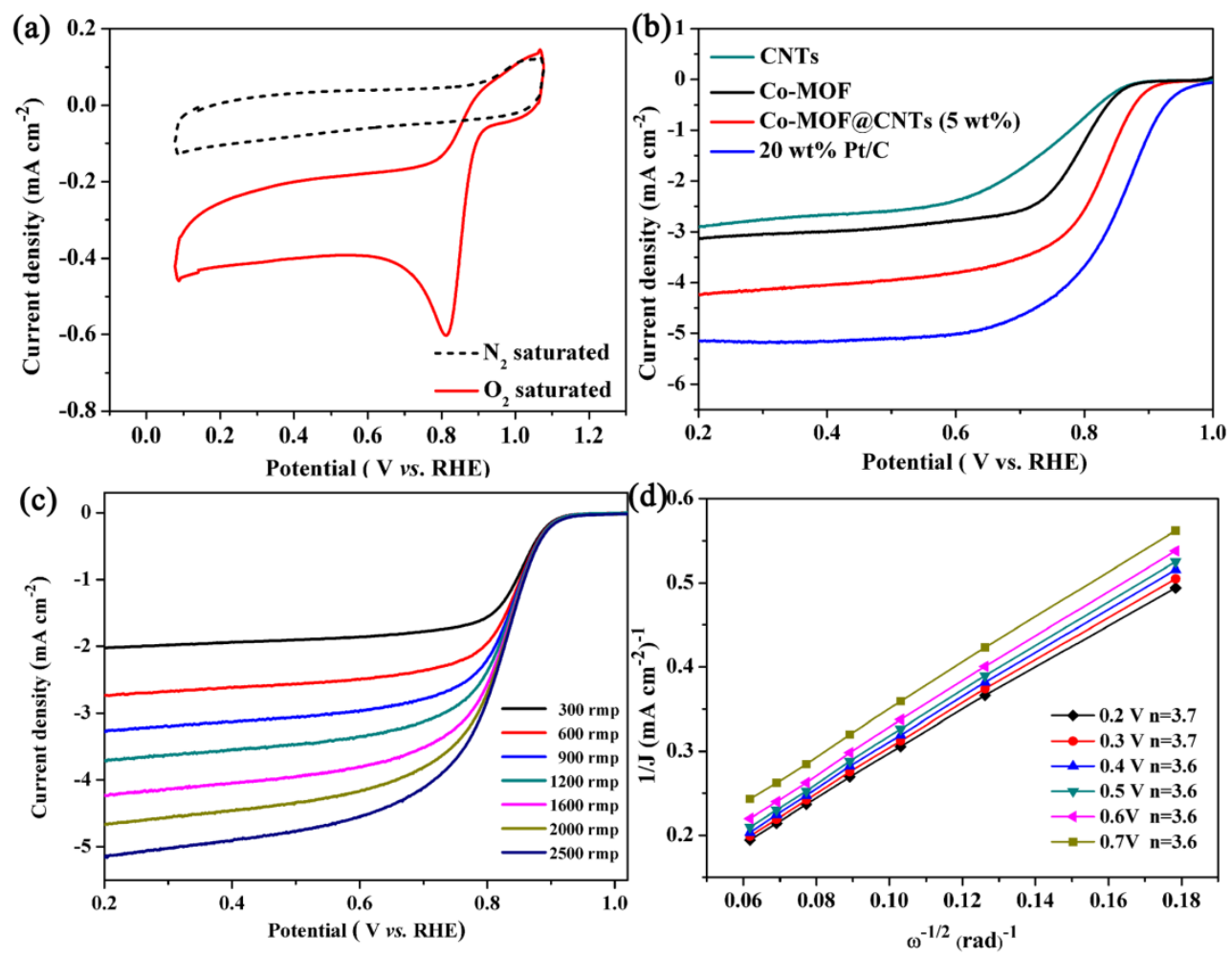

Fig. 8. (a) CVs of Co-MOF@CNTs (5wt\%) at a scan rate of $50 \mathrm{mV} \mathrm{s}^{-1}$, (b) ORR LSV curves of the CNTs, Co-MOF, Co-MOF@CNTs (5 wt\%) and 20 wt\% Pt/C (scan rate: $5 \mathrm{mV} \mathrm{s}^{-1}$; rotation rate: $1600 \mathrm{rpm}$ ), (c) ORR LSV curves of Co-MOF@CNTs (5 wt $\%$ ) at various rotation rates (scan rate: $5 \mathrm{mV} \mathrm{s}^{-1}$ ), and (d) Koutechy - Levich plots of Co-MOF@CNTs $(5 \mathrm{wt} \%)$ at various potentials.

Importantly, our hybrid exhibited superior durability to $20 \mathrm{wt} \% \mathrm{Pt} / \mathrm{C}$ catalyst in 0.1 
$\mathrm{M} \mathrm{KOH}$, with little decay in ORR activity over $40000 \mathrm{~s}$ of continuous operation (Fig. S11). In contrast, the $\mathrm{Pt} / \mathrm{C}$ catalyst delivered $62 \%$ decrease in activity in $0.1 \mathrm{M} \mathrm{KOH}$, giving lower long-term ORR currents than the stable currents sustained by the Co-MOF@CNTs (5\%) hybrid catalyst. The excellent electrocatalytic stability can be attributed to the novel frame nanostructures that anchored the homogenously distributed cobalt ion; in other words, the special $\mathrm{Co}(\mathrm{II})-\mathrm{N}-\mathrm{C}$ structure involving quaternary $\mathrm{N}$ atoms worked as the catalytic centres with superior catalytic performance. Meanwhile, the better stability also came from the high conductivity of CNTs with a unique $1 \mathrm{D}$ nanostructure, which were inserted into the Co-MOF and avoided active centres peeling off. This structure was advantageous over the case of carbon supported $\mathrm{Pt} / \mathrm{C}$ nanoparticles, which inevitably occurred carbon corrosion, and then the Pt nanoparticles would aggregate or detach from the substrate during prolonged electrochemistry process [29]. These results vindicated Co-MOF@CNTs $(5 \%)$ as a powerful bifunctional catalyst for both oxygen reduction and water oxidation.

\section{Conclusion}

In summary, highly stable Co-MOF@CNTs hybrid has been synthesized through a facile assembling process. In this composite, the CNTs were inserted in the Co-MOF polyhedral, forming hierarchical structure with building blocks. The hybrid exhibited comparable OER and ORR catalytic activity to $\mathrm{RuO}_{2}$ and $20 \mathrm{wt} \% \mathrm{Pt} / \mathrm{C}$ catalysts and superior stability. The prominent catalytic performance can be ascribed to the rational combination of the advantages of the hierarchical structure and the synergistic 
interaction between redox-active centers $\mathrm{Co}(\mathrm{II})$, organic ligands and CNTs. Importantly, assembling CNTs with Co-MOF was a smart choice to overcome the poor conductivity of MOF, which avoids the high-template pyrolytic process to form conductive carbon. Besides, CNTs could sustain the harsh oxidative environment of water oxidation without carbon corrosion. It was anticipated that the mild and affordable design of the bifunctional electrocatalysts would lead to improved strategies and hold great promise for future exploration in many other fields.

\section{Acknowledgments}

We are grateful to the reviewers for their insightful comments and valuable suggestions. This research was supported by the National Science Foundation of China (No. 21345003), the Fundamental Research Funds for the Central Universities (Grant no. lzujbky-2016-k08), the Natural Science Foundation of Gansu (145RJZA132), the Key Laboratory of Catalytic Engineering of Gansu Province and Resources Utilization, Gansu Province for financial support. 


\section{References}

[1] N.S. Lewis, D.G. Nocera, Proc. Natl. Acad. Sci. U.S.A., 103 (2006) 15729-15735.

[2] S. RF., Science, 324 (2009) 1257-1259.

[3] M. Park, H. Sun, H. Lee, J. Lee, J. Cho, Adv. Energy Mater., 2 (2012) 780-800.

[4] J.W.D. Ng, Y. Gorlin, T. Hatsukade, T.F. Jaramillo, Adv. Energy Mater., 3 (2013) 1545-1550.

[5] H. Dau, C. Limberg, T. Reier, M. Risch, S. Roggan, P. Strasser, ChemCatChem, 2 (2010) 724-761.

[6] J. Xu, D. Aili, Q. Li, E. Christensen, J.O. Jensen, W. Zhang, M.K. Hansen, G. Liu, X. Wang, N.J. Bjerrum, Energy Environ. Sci., 7 (2014) 820-830.

[7] Y. Bing, H. Liu, L. Zhang, D. Ghosh, J. Zhang, Chem. Soc. Rev., 39 (2010) 2184-2202.

[8] Y. Gorlin, T.F. Jaramillo, J. Am. Chem. Soc., 132 (2010) 13612-13614.

[9] M. Gong, Y. Li, H. Wang, Y. Liang, J.Z. Wu, J. Zhou, J. Wang, T. Regier, F. Wei, H. Dai, J. Am. Chem. Soc., 135 (2013) 8452-8455.

[10] X. Long, J. Li, S. Xiao, K. Yan, Z. Wang, H. Chen, S. Yang, Angew. Chem., Int. Ed., 126 (2014) 7714-7718.

[11] V. Artero, M. Chavarot-Kerlidou, M. Fontecave, Angew. Chem. Int. Ed., 50 (2011) 7238-7266.

[12] R.D.L. Smith, M.S. Prevot, R.D. Fagan, S. Trudel, C.P. Berlinguette, |J. Am. Chem. Soc., 135 (2013) 11580-11586.

[13] M. Bajdich, M. García-Mota, A. Vojvodic, J.K. Nørskov, A.T. Bell, J. AM. CHEM. SOC., 135 (2013) 13521-13530.

[14] M. Zhang, M.d. Respinis, H. Frei, Nat. Chem., 6 (2014) 362-367.

[15] Z. Zhuang, W. Sheng, Y. Yan, Adv. Mater., 26 (2014) 3950-3955.

[16] Y. Fang, X. Li, Y. Hu, F. Li, X. Lin, M. Tian, X. An, Y. Fu, J. Jin, J. Ma, J.Power Sources, 300 
(2015) 285-293.

[17] X. Lu, C. Zhao, J. Mater. Chem. A, 1 (2013) 12053-12059.

[18] A. Zhao, J. Masa, W. Xia, A. Maljusch, M.-G. Willinger, G. Clavel, K. Xie, R. Schlogl, W. Schuhmann, M. Muhler, J. Am. Chem. Soc., 136 (2014) 7551-7554.

[19] Z. Lu, W. Xu, W. Zhu, Q. Yang, X. Lei, J. Liu, Y. Li, X. Sun, X. Duan, Chem. Commun., 50 (2014) 6479-6482.

[20] S. Yang, X. Feng, S. Ivanovici, K. Mllen, Angew. Chem. Int. Ed., 49 (2010) 8408-8411.

[21] M.D. Krks, T. kermark, E.V. Johnston, S.R. Karim, T.M. Laine, B.-L. Lee, T. kermark, T. Privalov, B. kermark, Angew. Chem. Int. Ed., 51 (2012) 11589-11593.

[22] T.Y. Ma, S. Dai, M. Jaroniec, S.Z. Qiao, J. Am. Chem. Soc., 136 (2014) 13925-13931.

[23] S. Zhao, H. Yin, L. Du, L. He, K. Zhao, L. Chang, G. Yin, H. Zhao, S. Liu, Z. Tang, ACS NANO, 8 (2014) 12660-12668.

[24] N. Han, F. Zhao, Y. Li, J. Mater. Chem. A, 3 (2015) 16348-16353.

[25] J.-S. Li, S.-L. Li, Y.-J. Tang, M. Han, Z.-H. Dai, J.-C. Bao, Y.-Q. Lan, Chem. Commun., 51 (2015) 2710-2713.

[26] W. Xia, R. Zou, L. An, D. Xia, S. Guo, Energy Environ. Sci., 8 (2015) 568-576.

[27] X. Li, Y. Fang, X. Lin, M. Tian, X. An, Y. Fu, R. Li, J. Jin, J. Ma, J. Mater. Chem. A, 3 (2015) 17392-17402.

[28] S. Maass, F. Finsterwalder, G. Frank, R. Hartmann, C. Merten, J.Power Sources, 176 (2008) 444-451.

[29] S.-Y. Huang, P. Ganesan, H.-Y. Jung, B.N. Popov, J.Power Sources, 198 (2012) 23-29.

[30] K.S. Park, Z. Ni, A.P. Cote, J.Y. Choi, R. Huang, F.J. Uribe-Romo, H.K. Chae, M. OKeeffe, O.M. 
Yaghi, Proc. Natl. Acad. Sci. U.S.A., 103 (2006) 10186-10191.

[31] S.-W. Kim, J. Ryu, C.B. Park, K. Kang, Chem Commun (Camb), 46 (2010) 7409-7411.

[32] H.L. Yuan, Y.Q. Wang, S.M. Zhou, L.S. Liu, X.L. Chen, S.Y. Lou, R.J. Yuan, Y.M. Hao, N. Li, Nanoscale Res. Lett., 5 (2010) 1817-1821.

[33] L.T.L. Nguyen, K.K.A. Le, H.X. Truong, N.T.S. Phan, Catal. Sci. Technol., 2 (2012) 521-528.

[34] T.Y. Ma, S. Dai, M. Jaroniec, S.Z. Qiao, J. Am. Chem. Soc., 136 (2014) 13925-13931.

[35] Y. Li, P. Hasin, Y. Wu, Adv. Mater., 22 (2010) 1926-1929.

[36] J.D. Benck, Z.B. Chen, L.Y. Kuritzky, A.J. Forman, T.F. Jaramillo, ACS Catal., 2 (2012) 1916-1923.

[37] P. Li, Z. Jin, D. Xiao, J. Mater. Chem. A, 2 (2014) 18420-18427.

[38] D.U. Lee, J.-Y. Choi, K. Feng, H.W. Park, Z. Chen, Adv.Energy Mater., 4 (2014) 1301389.

[39] K. Wang, H. Wu, Y. Meng, Z. Wei, Small, 10 (2014) 14-31.

[40] Z. He, F. Mansfeld, Energy Environ. Sci., 2 (2009) 215-219. 


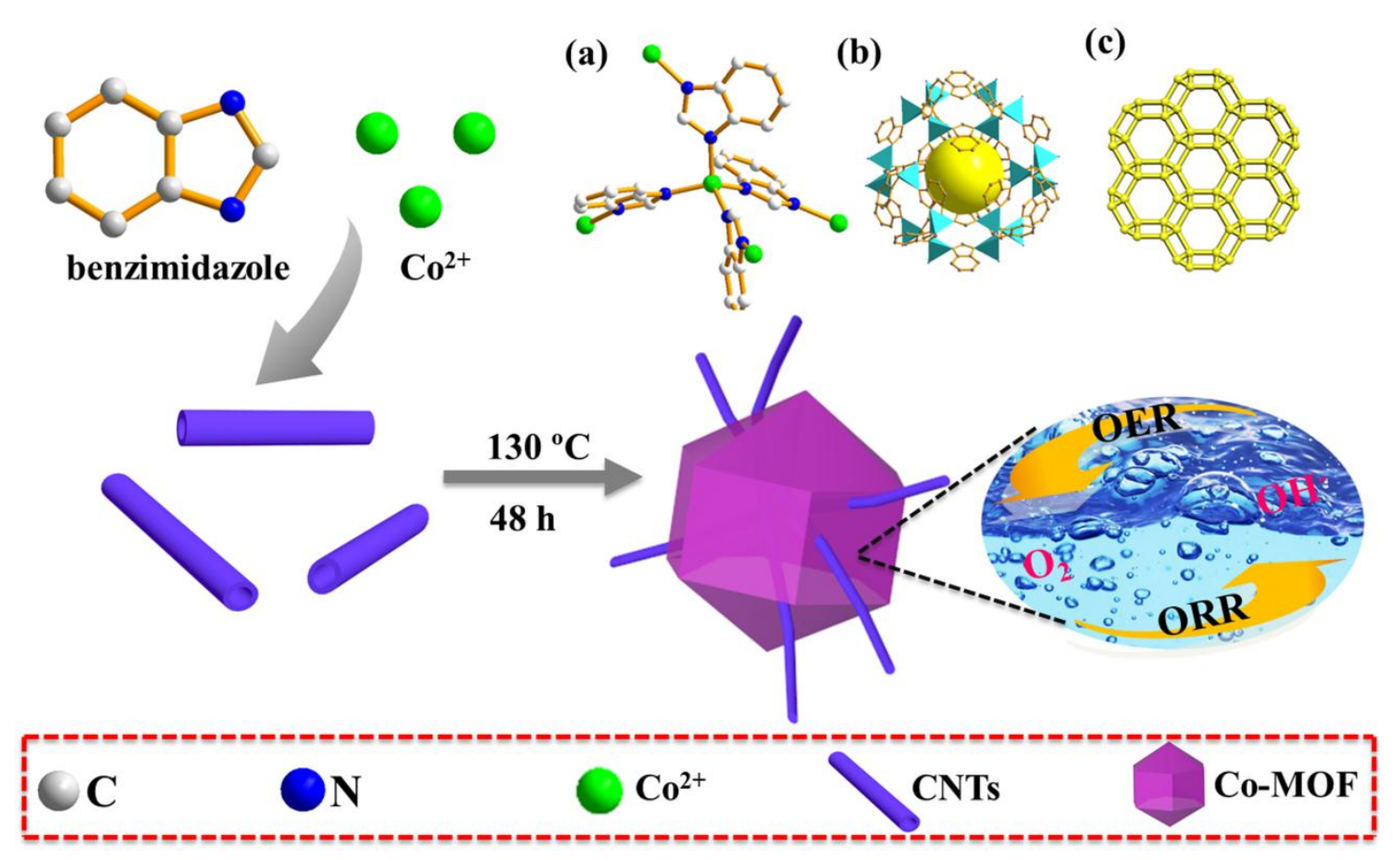

Scheme of synthesis of the catalyst Co-MOF@CNTs. 